Supplement of Atmos. Chem. Phys., 14, 9537-9554, 2014

http://www.atmos-chem-phys.net/14/9537/2014/

doi:10.5194/acp-14-9537-2014-supplement

(C) Author(s) 2014. CC Attribution 3.0 License.

(c) (i)

Atmospheric

Chemistry

and Physics

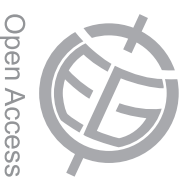

Supplement of

\title{
Hygroscopic properties and mixing state of aerosol measured at the high-altitude site Puy de Dôme (1465 m a.s.l.), France
}

H. Holmgren et al.

Correspondence to: K. Sellegri (k.sellegri@opgc.cnrs.fr) 
Table S1. Number of successful scans per measurement month for particle dry size 25, 35, 50, 75,110 and $165 \mathrm{~nm}$.

\begin{tabular}{rrrrrrrrrrrrr}
\hline $\begin{array}{c}\text { Particle } \\
\text { dry size }\end{array}$ & & & & & & & & & & & & \\
\hline $25 \mathrm{~nm}$ & 596 & 259 & 872 & 651 & 947 & 436 & 345 & 0 & 625 & 249 & 200 & 290 \\
$35 \mathrm{~nm}$ & 673 & 271 & 886 & 695 & 984 & 452 & 361 & 0 & 670 & 268 & 227 & 353 \\
$50 \mathrm{~nm}$ & 731 & 266 & 915 & 706 & 1002 & 448 & 369 & 0 & 669 & 277 & 228 & 341 \\
$75 \mathrm{~nm}$ & 714 & 274 & 917 & 718 & 994 & 450 & 369 & 0 & 661 & 276 & 253 & 322 \\
$110 \mathrm{~nm}$ & 630 & 252 & 936 & 721 & 1005 & 444 & 360 & 0 & 665 & 279 & 248 & 301 \\
$165 \mathrm{~nm}$ & 547 & 223 & 890 & 731 & 929 & 417 & 210 & 0 & 607 & 248 & 245 & 269 \\
\hline
\end{tabular}

